\title{
Lunate Bone
}

National Cancer Institute

\section{Source}

National Cancer Institute. Lunate Bone. NCI Thesaurus. Code C12786.

The bone in the proximal row of carpal bones that lies between the scaphoid and triquetral bones. 